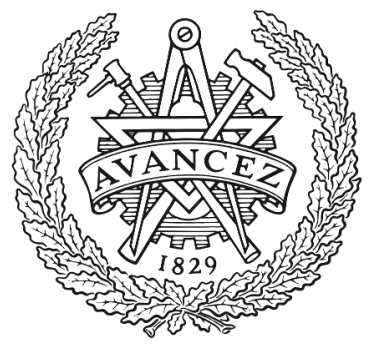

CHALMERS

UNIVERSITY OF TECHNOLOGY

\title{
Managing complexity through integrative tactical planning in engineer-to-order environments: insights from four case studies
}

Downloaded from: https://research.chalmers.se, 2023-04-26 14:16 UTC

Citation for the original published paper (version of record):

Shurrab, H., Jonsson, P., Johansson, M. (2022). Managing complexity through integrative tactical planning in engineer-to-order environments:

insights from four case studies. Production Planning and Control, 33(9-10): 907-924.

http://dx.doi.org/10.1080/09537287.2020.1837937

N.B. When citing this work, cite the original published paper. 


\title{
Managing complexity through integrative tactical planning in engineer-to-order environments: insights from four case studies
}

\author{
Hafez Shurrab (D), Patrik Jonsson (D) and Mats I. Johansson \\ Department of Technology Management and Economics, Chalmers University of Technology, Gothenburg, Sweden
}

ABSTRACT

Fulfilling customer orders in engineer-to-order (ETO) settings entails customization and, thus, greater complexity: detail and uncertainty. Tactical planning aims at demand-supply (DS) balancing by ensuring cross-functional integration (CFI), which incorporates coordination as one dimension. This study uses a case study approach to identify the key coordination mechanisms applied in the customer order fulfilment processes (COFPs) to mitigate the negative impact of complexity on DS balancing in four ETO-oriented settings. Within-case analyses identify the applied mechanisms, and a cross-case analysis elaborates on how they influence the detail and uncertainty in decision-making and problemsolving activities. Findings suggest a positive effect of formalized activity sequences, balanced team compositions, effective task designs and supportive information systems (ISs); and a positive (but contingent) effect of the other mechanisms. Future research may address other CFI dimensions (collaboration), statistically test the findings, or qualitatively deepen the understanding of the forms and impacts of individual mechanisms.
ARTICLE HISTORY

Received 26 October 2019

Accepted 13 May 2020

\section{KEYWORDS}

Order fulfilment process; integration; complexity; tactical planning; engineerto-order

\section{Introduction}

A customer order fulfilment process (COFP) embraces several tactical-level planning activities that respond to current and future customer enquiries, which are key demand-supply (DS) balancing activities in engineer-to-order (ETO) manufacturing settings (Carvalho, Oliveira, and Scavarda 2015). From a supply chain (SC) perspective, DS balancing is crucial for ETO businesses, not only because profit margins can easily be wiped out if demand falls behind supply capacity (Olhager 2010), but also due to the amplified devastating bullwhip effect generated from an unbalanced demand and supply situation (Lee, Padmanabhan, and Whang 1997; Sun and Yen 2005).

According to Oliva and Watson (2011), DS balancing at a tactical level requires an intensive cross-functional integration (CFI) between demand- and supply-facing functions. In the ETO SCs, the COFP genuinely needs CFI to effectively and consistently balance demand and supply (Shurrab, Jonsson, and Johansson 2020). One reason is that the fierce competition on winning contracts calls for minimizing the delivery leads times through higher concurrency. This leads to more interdependencies across functions and between activities. Such interdependency demands substantial CFI (Mello, Strandhagen, and Alfnes 2015). Furthermore, the complexity of ETO SCs is intrinsically high in terms of detail and uncertainty due to having to execute product customizations after the entry of customer enquiries (Wikner and Rudberg 2005; Birkie and Trucco 2016).

Product customiations require capacity adaptations and actions such as buying and re-engineering of equipment, recruiting engineers, and obtaining offers from suppliers (Gosling et al. 2015). Several studies about complexity management provide rich insights into how clusters of practices help to reduce and absorb complexity (e.g. Serdarasan 2013; Fernández Campos, Trucco, and Huaccho Huatuco 2019). Following such efforts, this study aims at identifying CFI mechanisms applied in the COFP to mitigate the negative impact of complexity on DS balancing in the ETO SCs. Accordingly, the following research questions are addressed:

1. RQ1: What are the CFI mechanisms applied in tacticallevel planning activities in ETO settings?

2. RQ2: How do these mechanisms mitigate the negative impact of complexity on DS balancing?

Thus, to answer the research questions, an exploratory multiple case study focussing on four ETO-oriented companies is conducted. Four within-case analyses are performed to identify the CFI mechanisms applied in the COFPs of the cases. A cross-case analysis then focuses on the similarities and differences between the cases concerning the applied CFI mechanisms to capture how CFI mechanisms mitigate the negative impact of complexity (detail and uncertainty)

CONTACT Hafez Shurrab hafez@chalmers.se Department of Technology Management and Economics, Chalmers tekniska högskola, Vera Sandbergs Allé 8 , Building: Vasa Hus 3, Floor: 3, Gothenburg 41296, Sweden

(C) 2020 The Author(s). Published by Informa UK Limited, trading as Taylor \& Francis Group

This is an Open Access article distributed under the terms of the Creative Commons Attribution License (http://creativecommons.org/licenses/by/4.0/), which permits unrestricted use, distribution, and reproduction in any medium, provided the original work is properly cited. 
on DS balancing. The remaining sections describe the methodology, case analysis, discussions and concluding remarks.

\section{Literature review}

\subsection{Supply chain complexity}

Some factors drive the complexity of a system generating additional detail (or structural) and dynamic complexity. This study employs detail and uncertainty to represent the essence of detail and dynamic complexity. Detail complexity represents the number of entities embedded in a system, whereas dynamic complexity represents the 'situations where cause and effect are subtle and ... the effects over time of interventions are not obvious' (Senge 1998, 71). For Serdarasan (2013), the uncertainty related to time and randomness represents the essence of dynamic complexity. According to Galbraith $(1977,37)$ 'uncertainty is the difference between the amount of information required to perform the task and the amount of information already possessed by the organization.' Therefore, higher uncertainty entails more information that decision-makers need to process to execute tasks and achieve a certain level of performance.

Bozarth et al. (2009) categorized the complexity drivers into factors that increase detail and uncertainty downstream, upstream, and within internal manufacturing.

The downstream drivers include the number of customers, heterogeneity in customer needs, and demand variability. According to Berry et al. (2011), more customers imply more tasks to manage customer relationships and demand. Various customer needs imply various order winners and qualifiers, which increases potentials for conflicts in manufacturing tasks and misalignment with customer needs (da Silveira 2005). Demand variability may increase the uncertainty upstream. For instance, a lack of coordination along the SCs in ordering policies causes the bullwhip effect (Chen et al. 2000).

The internal manufacturing drivers include the number of products and parts, low volume production, and manufacturing schedule instability. More unique products and parts entail various manufacturing tasks (Closs et al. 2008). Low volume batch production increases the number of unique jobs in manufacturing. More uniqueness across jobs causes more variability in manufacturing, leading to higher uncertainty. According to Berry et al. (2011), unexpected absenteeism and machine failure influence the instability in production by increasing the scheduling uncertainty related to daily production and material plans.

The upstream drivers include the number of suppliers, length and unreliability of supplier lead times, and supplier globalization (Bozarth et al. 2009). Adding suppliers increases not only the number of information flows, physical flows and relationships, but also the uncertainty about lead time. Long and unreliable supplier lead times call for longer planning horizons and more detail due to uncertainty (Berry et al. 2011). Finally, higher supplier globalization implies higher uncertainty in areas like import and export laws, currency valuations, and cultural differences (Cho and Kang 2001).

\subsection{Demand-supply balancing activities in ETO settings}

Customer order fulfilment in ETO settings is project-based, and DS balancing occurs at an aggregate multi-project level (Carvalho, Oliveira, and Scavarda 2015). According to Shurrab, Jonsson, and Johansson (2020), tactical planning in ETO settings encompasses screening, customization, workload analysis, review, and contracting as activity domains.

Upon the screening stage, functions cooperate to prioritize enquiries, assigning teams to analyse the underlying customization and production more deeply (Cooper and Budd 2007). Engineers identify the design requirements that other functions like production and SC review afterwards. This entails determining the required external design and technology development services and assessing the production and economic feasibility.

The order customization tasks lead to finalizing the product- and production-related designs, and the workload analysis outcomes represent paths of parallel interdependent execution activities and corresponding cost and duration estimates. Then, the order review activities examine the generated plans and estimates, emphasizing commercial aspects, such as competitiveness and financial risks, which leads to order acceptance only if the enquiries in question are satisfactory from strategic, technical and capacity perspectives.

This study divides the COFP into problem-solving and decision-making activities. Problem-solving activities generate alternatives, whereas decision-making activities narrow down the alternatives and develop corresponding scenarios. Problem-solving activities include preliminary activity cost and duration assessments and resource allocations for pre-contract activities in the screening stage; procuring capacity for pre-contract activities, product engineering and process engineering in the customization stage; resource allocations for post-contract activities, procuring capacity for post-contract activities and developing cost and duration estimates in the workload analysis stage; and aggregate review of the parallel delivery plans, pricing customer orders and offer documentations in the review stage.

Decision-making activities include prioritizing orders and assigning capacity for pre-contract activities in the screening stage; assigning external capacity for pre-contract activities, selecting design alternatives and selecting manufacturing methods in the customization stage; determining internal and external capacity for post-contract activities in the workload analysis stage; and determining profit margins and changes in design and delivery settings in the review stage.

\subsection{Cross-functional integration}

The ability to process more detail and uncertainty in the COFP depends on how CFI enables a higher interaction frequency and greater amounts of interacting entities and allow for less cause-and-effect ambiguity, respectively (Galbraith 1977). Kahn (1996) suggests interaction and collaboration as CFI dimensions, where structured cross-functional activities (e.g. communication exchange) represent forms of interaction, while the relationships describing how functions 
'work together, have mutual understanding, have a common vision, share resources, and achieve collective goals' (139) represent forms of collaboration. This study conceptualizes CFI somewhat differently, perceiving interactions as mere reciprocal actions that can signal a structured setting of coordination or an affective behaviour of collaboration, since interaction is 'an occasion when two or more people or things communicate with or react to each other' (Combley 2011, 446).

Although Fernández Campos, Trucco, and Huaccho Huatuco (2019) suggest coordination and collaboration to manage the negative impact of detail and dynamic complexity on the SC, this study solely addresses coordination due to its greater relevance to tactical-level planning processes (e.g. Tuomikangas and Kaipia 2014). Chow, Heaver, and Henriksson (1995) explicitly relate CFI to coordinating activities in the SC.

Coordination and CFI are distinct terms. While coordination is the process of aligning decentralized decisions, e.g. resource allocations, with the system objectives by securing proper information quality and incentives to various decision-makers across hierarchies, CFI goes beyond coordination to encompass the determination of the system objectives themselves (Oliva and Watson 2011). Previous SC research at large operationalizes CFI through mechanisms, such as centralization, standardization, formalization, cross-functional teams (CFTs), task forces, integrator roles, and information system (IS) support (see Turkulainen and Ketokivi 2012). A mechanism is 'a way of doing something that is planned or part of a system' (Combley 2011, 533).

Centralization refers to the distribution of decision-making authority (Chow, Heaver, and Henriksson 1995), while formalization describes how formal rules and policies govern decisions and relationships independently of the personal attributes of individuals (Daugherty, Stank, and Rogers 1992). Standardization refers to the similarity of using resources internally or across firms (Chow, Heaver, and Henriksson 1995).

Holland, Gaston, and Gomes (2000) suggest CFTs, individual integrators, and task design as key CFI mechanisms when developing new products. The way teams are composed, and the way team members are aligned and located, can reflect the quality (degree) of being integrative (Mathieu et al. 2014). Moreover, Nihtilä (1999) found that successful companies dedicate individual integrators and CFTs when developing new products to communicate product-specific strategic objectives across departments and facilitate interorganizational interactions with customers and suppliers.

According to Hirunyawipada, Beyerlein, and Blankson (2010), the design of a task determines the degree to which the task can be integrative. An integrative task design allows for more problem-solving orientation, more complete information, greater concurrency between tasks, and increased cohesion (i.e. division of tasks specialist and generalist domains) (Galbraith 1977). Finally, the way ISs support crossfunctional information processing increases how much these systems are integrative (Turkulainen and Ketokivi 2012).

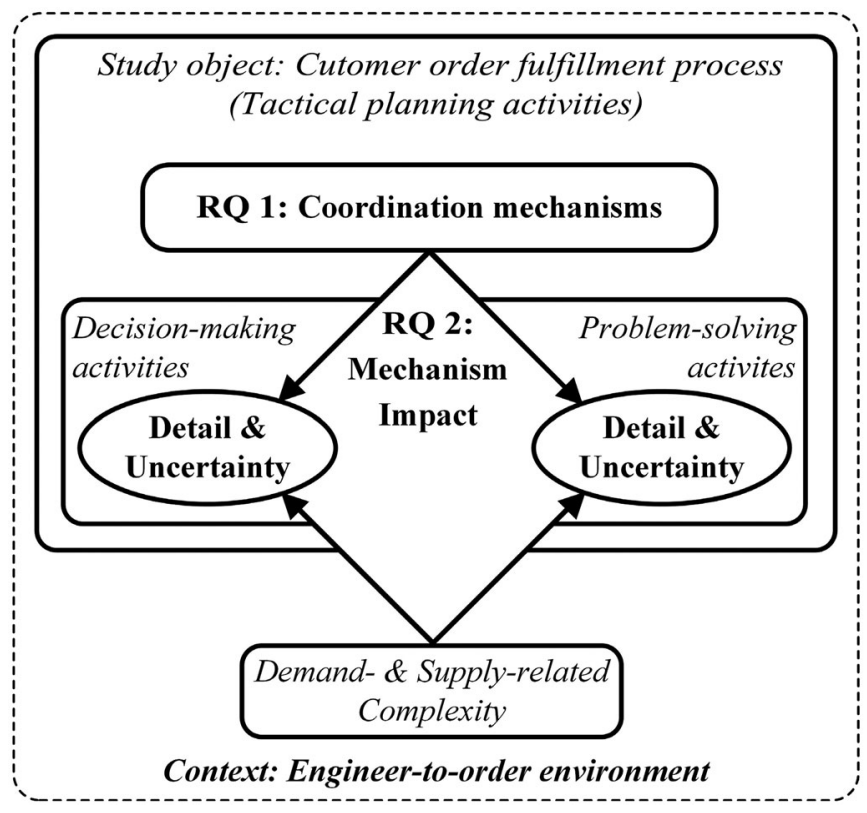

Figure 1. Conceptual framework of the study problem.

\subsection{Conceptual framework}

Figure 1 presents the conceptual framework of this study. In line with Bozarth et al. (2009), the SC complexity either stems from demand or supply as drivers that increase the detail and uncertainty of a system (Senge 1998; Serdarasan 2013). In this study, the decision-making and problem-solving activities of the COFP represent the study object. To manage the growing detail and uncertainty, these activities apply several coordination mechanisms to facilitate DS balancing. The enhanced cross-functionality of DS balancing interactions implies that the embedded coordination mechanisms enable the processing of additional details and uncertainties (Tuomikangas and Kaipia 2014). Therefore, RQ1 focuses on identifying the coordination mechanisms applied in the decision-making and problem-solving activities within the COFP, while RQ2 studies the impact of these mechanisms on the detail and uncertainty in the process considering the contextual impact, if applicable.

\section{Methodology}

This section describes case selection and data collection and analysis.

\subsection{Case selection}

Due to the limited conceptualization and empirical research on the relationship between CFI mechanisms and the negative impact of complexity on DS balancing, this study adopts an exploratory theory-building approach (Eisenhardt 1989), investigating the COFP in four ETO-oriented settings (see Table 1). Multiple case studies are suitable to investigate 'how' and 'why' contemporary events occur (Yin 2009).

Learning is possible when studying multiple cases through elaborating on homogenous and heterogenous case characteristics (Voss, Tsikriktsis, and Frohlich 2002). To ensure homogeneity, all case companies needed to have an ETO strategy in line 
Table 1. Sample characteristics.

\begin{tabular}{|c|c|c|c|c|}
\hline Characteristic & Build & $3 P L$ & Aero & Auto \\
\hline Market segment & Residential buildings & Automated warehouses & Engine components & Customized vehicles \\
\hline SC position & $\mathrm{OEM}^{\mathrm{a}}$ & $3 P L^{b}$ & First-tier supplier & OEM \\
\hline ETO orientation & $100 \%$ & $100 \%$ & Up to $60 \%$ & Up to $30 \%$ \\
\hline Number of employees & 3732 & 1171 & 2100 & 8178 \\
\hline Net sales in (€M) & 1473 & 48.5 & 582 & 2423 \\
\hline
\end{tabular}

${ }^{a}$ Original equipment manufacturer.

${ }^{\mathrm{b}}$ Third-party logistics.

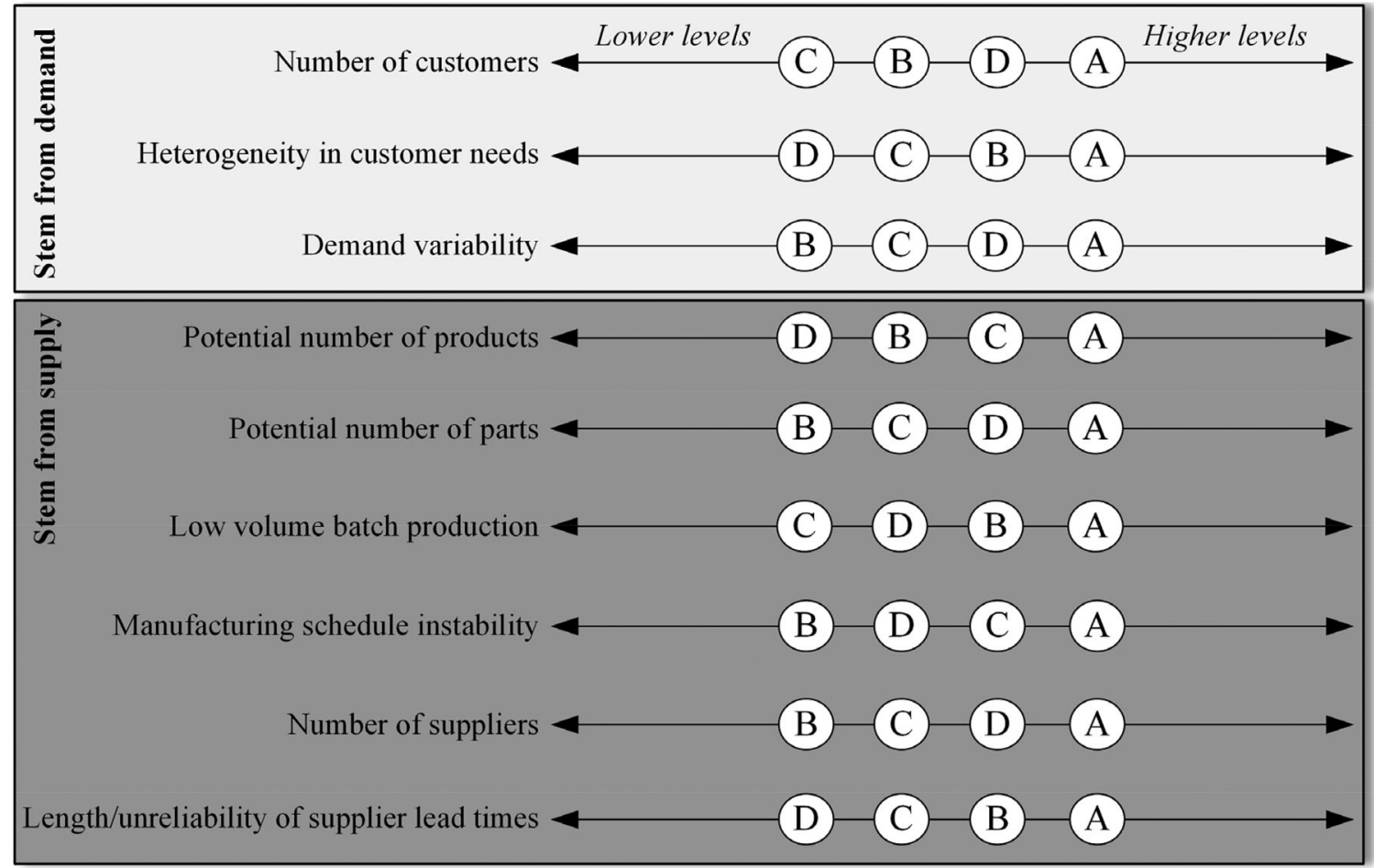

A: Build; B: 3PL; C: Aero; D: Auto

Figure 2. Sample settings of complexity.

with definitions from the literature (see Gosling and Naim 2009), whereby firms start customizing products after receiving the respective customer orders. Since studying the COFP and the applied CFI mechanisms requires in-depth enquiries, the number of case companies needed rationalization, which was possible through ensuring cross-case heterogeneity (Eisenhardt 1989). To ensure heterogeneity, the cases needed to present variability in terms of the complexity drivers discussed by Bozarth et al. (2009) as shown in Figure 2. Initially, the study considered the case companies, Build and 3PL, which are purely driven by ETO strategies. Build has greater complexity than 3PL on all drivers. To ensure theoretical replication, Yin (2009) suggests cases need to vary in the dimensions of relevant interest, i.e. the complexity configurations in this study. Therefore, the study included additional case companies, Aero and Auto, with varying complexity levels compared to $3 \mathrm{PL}$ to further explore and validate the generated insights from Build and 3PL.

According to Yin (2009), adding cases is valuable if this entails highlighting or reducing the differences between the research units. In this study, the cases needed to have similar COFP configurations to ensure cross-case comparability. Yet, the cases needed to show variability in terms of complexity and CFI to allow for inferring the impact of CFI mechanisms on the detail and uncertainty stemming from demand and supply. Using certain CFI mechanisms in certain complexity settings may raise questions concerning the increasing need for $\mathrm{CFI}$ and its contingent impact. Figure 2 shows the relative differences between the selected cases derived during the case screening and pilot interviews, capitalizing on related materials and plant tours that describe each case's products, customers, and manufacturing infrastructure.

\subsection{Data collection}

Using semi-structured interviews as the primary data collection technique, the study involved 19 managers on 27 occasions, for an average of 90 minutes per interview. Through exploring relevant process events, understanding the mechanisms involved becomes possible (Closs et al. 2008), and by covering key topics, exploring new and developing areas becomes possible (Yin 2009). Accordingly, selecting interviewees followed the COFP logic, starting with key individuals, who know the most about all the phases, see Table 2, which needed three to four occasions along with sharing many process-related descriptions. This led to mapping the cross-functional interactions within the respective COFPs. 
Table 2. The profile of selected interviewees.

\begin{tabular}{|c|c|c|c|}
\hline Orientation & Interviewee position & $\begin{array}{l}\text { Key role in the customer order } \\
\text { fulfilment process }\end{array}$ & Case \\
\hline \multirow[t]{2}{*}{ Demand } & Head of key account managers ${ }^{a}$ & $\begin{array}{l}\text { Directs order fulfilment, assigns key } \\
\text { account managers and selects and } \\
\text { prioritizes tender enquiries. }\end{array}$ & Build \\
\hline & Head of partnering & $\begin{array}{l}\text { Directs order fulfilment for } \\
\text { partnering projects. }\end{array}$ & Build \\
\hline Demand & Head of marketing ${ }^{b}$ & $\begin{array}{l}\text { Directs order fulfilment, assigns key } \\
\text { account managers and selects and } \\
\text { prioritizes tender enquiries. }\end{array}$ & $3 \mathrm{PL}$, Auto \\
\hline Demand & Programme director $^{c}$ & $\begin{array}{l}\text { Directs order fulfilment, assigns key } \\
\text { account managers and selects and } \\
\text { prioritizes tender enquiries. }\end{array}$ & Aero \\
\hline Demand \& Supply & S\&OP analyst ${ }^{d}$ & $\begin{array}{l}\text { Coordinate alignment between } \\
\text { demand and supply planning. }\end{array}$ & Aero, Auto \\
\hline Supply & Production development manager & $\begin{array}{l}\text { Aligns tender enquiries with } \\
\text { production capabilities, and } \\
\text { reviews designs and delivery plans. }\end{array}$ & Build \\
\hline Supply & Senior logistics specialist & $\begin{array}{l}\text { Coordinate capacity planning under } \\
\text { order customization and review. }\end{array}$ & Aero, Auto \\
\hline Supply & Design/resource planner & Assigns bidding teams. & Build, Aero \\
\hline Supply & Production manager & $\begin{array}{l}\text { Validates specs of tender requests } \\
\text { against production feasibility } \\
\text { and economics. }\end{array}$ & Build \\
\hline Supply & Project manager & $\begin{array}{l}\text { Coordinates order fulfilment and } \\
\text { supports production and } \\
\text { procurement functions. }\end{array}$ & Build, 3PL, Auto, Aero \\
\hline
\end{tabular}

The key respondents helped in identifying additional interviewees from the supply- and demand-facing functions including marketing, engineering, production, and project management to validate and gain more details about the cross-functional interactions and the elicited CFI mechanisms (RQ1). All respondents elaborated on the role of the applied CFI mechanisms (such as those in forms of practices and policies) in managing the detail and uncertainty stemming from demand and supply (RQ2).

To ensure consistency, the study used an interview guide (see Appendix 1), which consisted of semi-structured questions based on the literature on the conceptual framework topics. The authors and related practitioners evaluated and adapted the guide as suggested by Yin (2009). Posing the questions was in English, but the discussion was in Swedish.

Unfortunately, in some occasions, some respondents did not allow recording the interviews, but the authors collected notes, impressions, and ideas that occurred during these events, and added them to the case study database (Barratt, Choi, and Li 2011). Moreover, most of the interviews occurred in the presence of one of the authors, which allowed for observations (Voss, Tsikriktsis, and Frohlich 2002). Observations add to the source of data, which contributes to the research validity (Eisenhardt 1989).

The study considered data triangulation using both archival data and observations to ensure reliability and validate the interview descriptions. According to Voss, Tsikriktsis, and Frohlich (2002), triangulation by increasing the sources of data helps to understand a phenomenon better. The authors referred to formal and informal documents related to the COFP, such as policies, reports, instructions, guidelines, checklists, and presentation slides to assess the alignment with the interviewees' perceptions and opinions. Moreover, the authors conducted follow-up conversations with the respondents via e-mails or phone calls whenever they discovered potential discrepancy or missing information.

\subsection{Data analysis}

The unit of analysis was the COFP. The study adopted a content analysis method (Voss, Tsikriktsis, and Frohlich 2002), departing from the conceptual framework in Figure 1 and using spreadsheets. The authors subjectively interpreted and systematically classified and coded content of textual data into themes or patterns (Hsieh and Shannon 2005).

The conceptual framework enabled the initial categorization of the case descriptions. Thus, to answer RQ1, the authors used the categories of CFI mechanisms as sorting categories (Eisenhardt 1989), defining the applied settings of CFI mechanisms throughout the process. To answer RQ2, the authors compared the process descriptions across the cases (Yin 2009). Analysing the cross-case similarities and differences concerned with the applied CFI mechanisms against the complexity settings in place allowed for inferring answers to $\mathrm{RQ2}$.

\section{Empirical results}

This section presents the results of within- and cross-case analyses. Figures 3-6 present the COFPs of the cases as swim-lane diagrams. Brief descriptions about the applied CFI mechanisms follow. Table 3 in Section 4.2 summarizes the results from the within- and cross-case analyses.

\subsection{Within-case analyses: integrative mechanisms}

Figures 3-6 present the cross-functional interactions as decision-making and problem-solving activities (diamonds and 


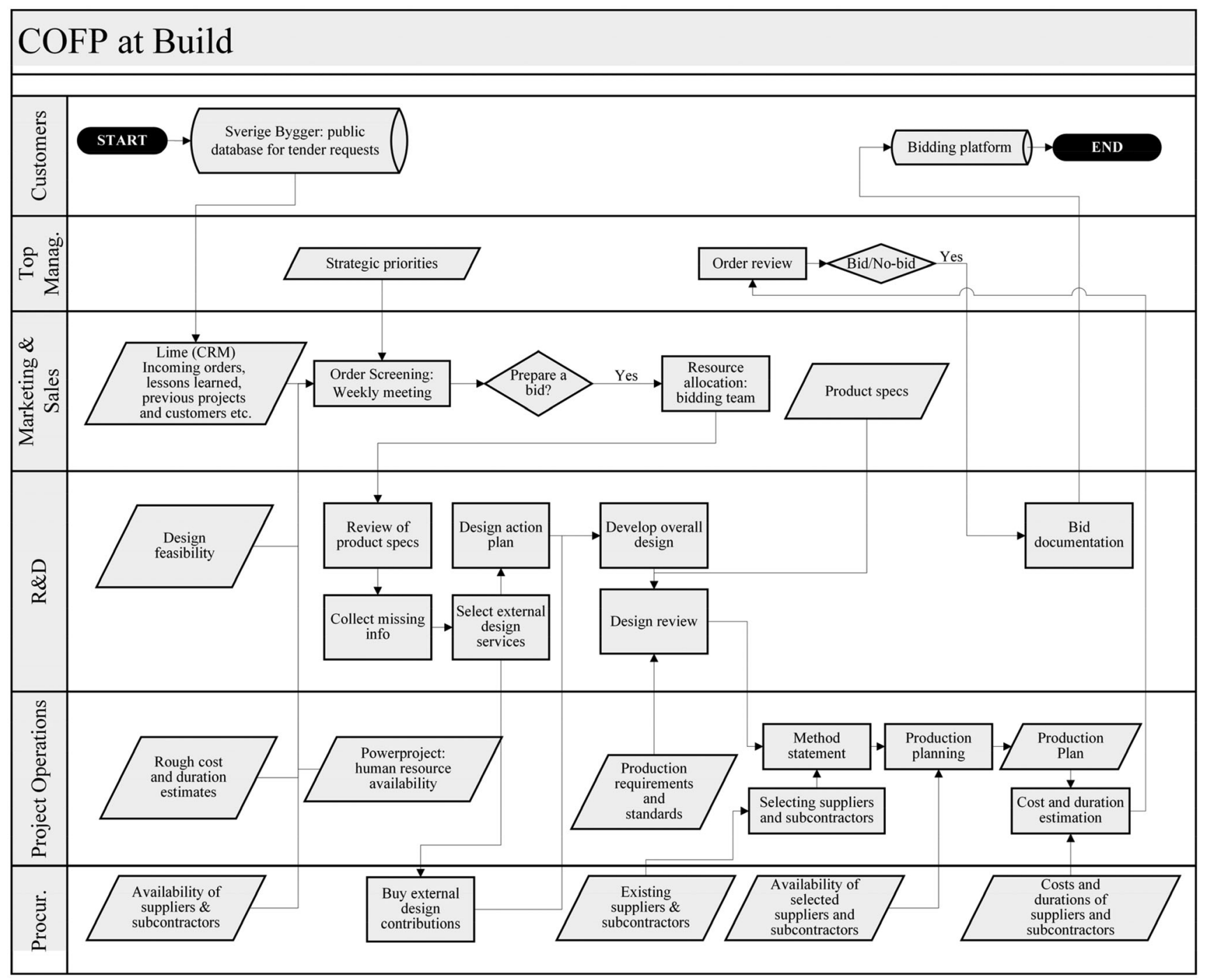

Figure 3. Cross-functional interactions within COFP at Build.

rectangles, respectively) managed by certain functions (rows) that, in turn, receive inputs (parallelograms) from other functions or through external information platforms (cylinders) to process information and result in outcomes; that is, decisions or solutions and alternatives. The ovals represent either the starts or the ends of information flows, while the arrows show the direction of information transmission.

The captured details regarding the settings of the crossfunctional interactions within the COFPs of the cases (Figures 3-6) revealed various applied forms of integrative mechanisms. Table 3 summarizes all such forms. If the authors identify a relevant form of integrative coordination within a certain COFP stage at a case, the table refers to this stage in the respective case cell as ' $S,{ }^{\prime}{ }^{\prime} \mathrm{C}$ ', ' $\mathrm{W}$ ' or ' $\mathrm{R}$ ' symbolizing screening, customization, workload analysis, and review, respectively. The table shows 'COFP' (or 'N/l') when a form of integrative coordination is identified in all stages (or not identified at all).

Three integrative forms of centralization were observed. One form is that a few people from the marketing department exclusively make the decisions associated with selecting enquiries and core team members. 'Sales as a function is centralised since the decisions concerning how the various plants located in different regions to serve various business units should avoid sub-optimization scenarios in which some plants may end up competing against each other' (a programme director at Aero). At 3PL, the decisions of selecting options related to customization (design) and workload analysis (production) are also centralized. Centralizing such decisions 'reduces the disputations across departments concerning the prioritisation or selection criteria and motivates the [COFP] team members to be productive and more focused on what has been already set by the marketing and top management as objectives' (the head of marketing at 3PL). Another integrative form of centralization is the companywide obligation to select suppliers from a limited supply base, which 'allows for focused discussions across departments regarding the product design and production planning' (an S\&OP analyst at Auto). Moreover, 'establishing relationships with new suppliers is often a lengthy process and dealing with them implies dealing with substantial uncertainty and hidden costs' (a senior logistics specialist at Aero).

Three integrative forms of standardization were found in terms of processes, documentation, and team formation. 


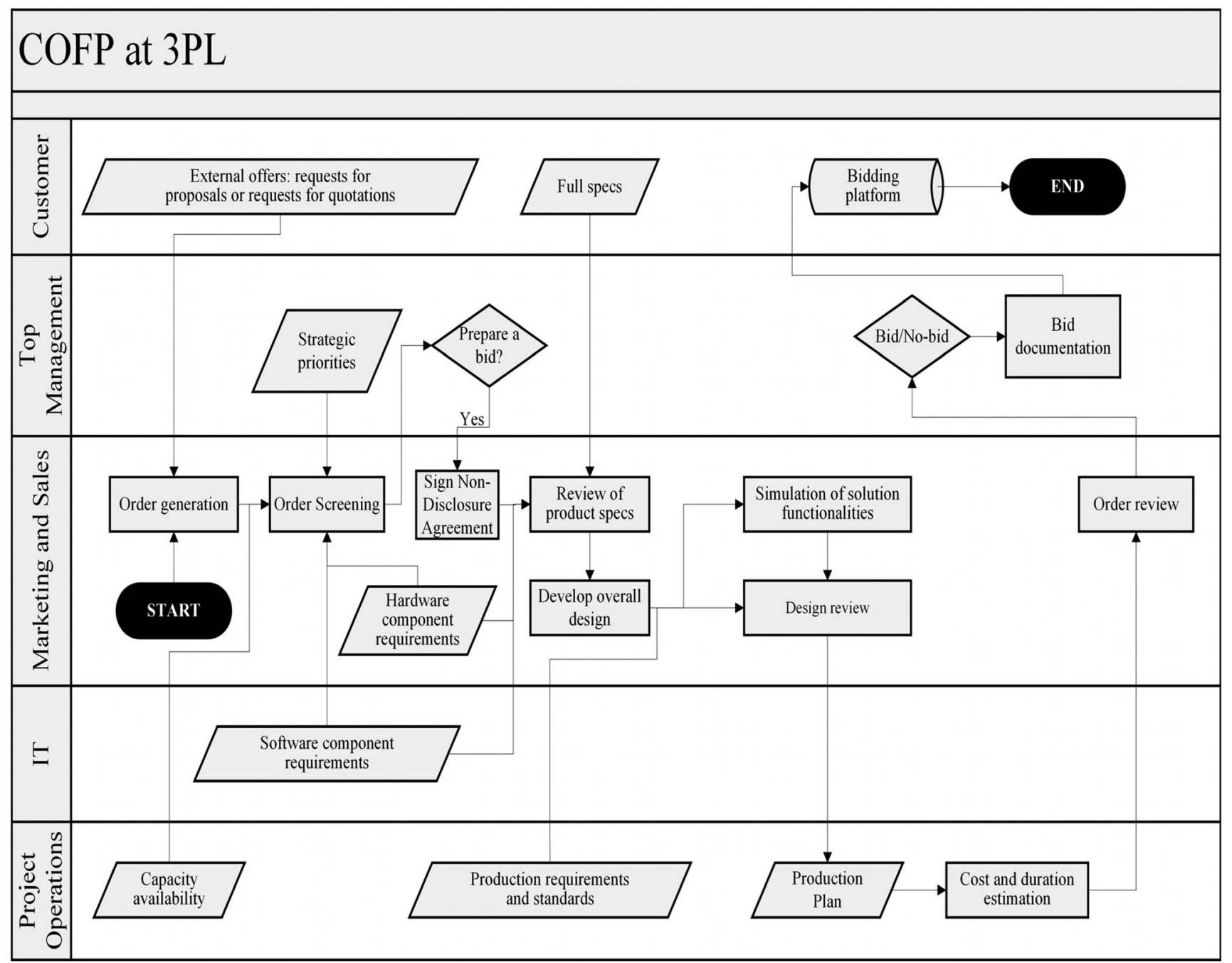

Figure 4. Cross-functional interactions within COFP at 3PL.

'Standardising the activity sequences of the entire [COFP] guides all tendering teams towards preparing strategically aligned competitive offers' (programme director at Aero). For the same reason, the roles and responsibilities of the tendering team members are standardized to ensure efficient tender preparation by distributing the best practices of team problem-solving, as stated in the documented instructions at Auto. As for standardizing documentation, 'there is a necessity to have a common language internally and with both suppliers and customers as many technical specifications are communicated along the [COFP], which can be documented in many different ways' (the head of marketing at 3PL). 'Industry-specific documentation standards evolved over time because of a long-term relationship between buyers and suppliers to speed up the inter-organisational communication' (a resource planning manager at Aero).

Four integrative forms of formalization were identified. 'Clear and specific statements of departmental responsibilities serve as a formal way of informing those involved in the [COFP] about whom to refer to' (a head of key account managers at Build). Associating formal performance measures with the COFP, such as hit-rates (the probabilities of winning orders), profit margins, order changes, resource utilization, market share and other product- or contract-specific measures, was also found to be integrative. 'Having formal measures like hit-rates ... motivate the [COFP] team members to cooperate with each other, as these measures help to reach consensus on the tasks teams should prioritise to improve their performance' (a production development manager at Build).

Planning the COFP work through formal stage gates was found to be integrative. 'The [COFP] stage gates receive attention across the functions since the top managers formally declare their approvals as signoffs upon these gates' (a programme manager at Aero). Additionally, formalizing certain meetings was also found to be integrative. 'Making key meetings-which have substantial consequences on the stage-gate decisions-mandatory to attend, reasonably frequent, and well-structured is a way to push the departments towards learning about, discussing, and reviewing each other's results, which gives no excuses for not coordinating their cross-functional activities' (a project manager at Build).

Regarding individuals who act as key integrators, four integrative management practices were elicited. '[COFP] is highly customer-oriented, and integrative marketing managers recruit individuals with diversified technical and commercial backgrounds who are either located nearby or equipped with prior experience from key customers' (a programme 


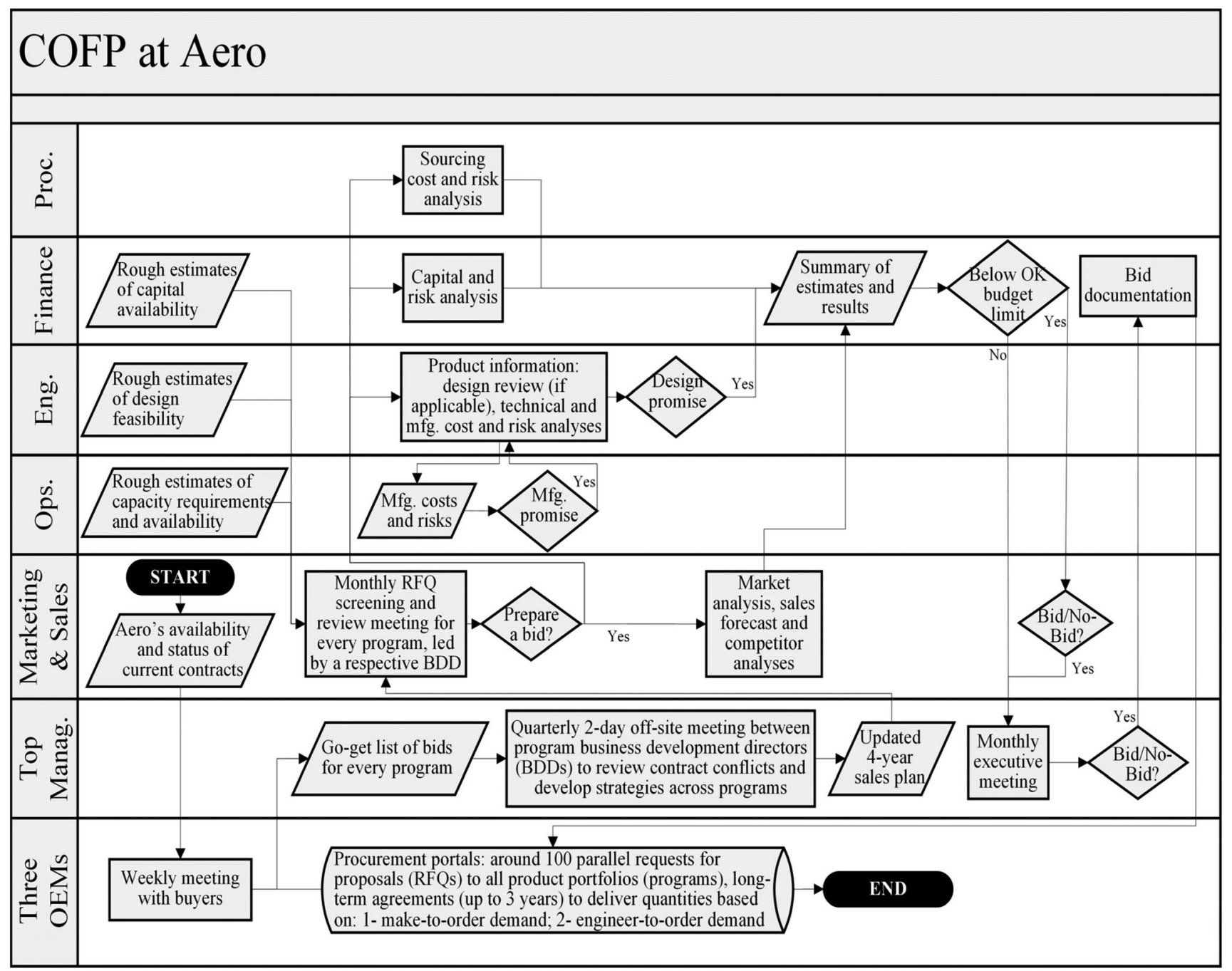

Figure 5. Cross-functional interactions within COFP at Aero.

manager at Aero). Another integrative practice adopted by the COFP team managers who act as individual integrators is to 'ensure systematic gathering and usage of information about existing or previous customers' (a regional head of partnering at Build). This practice maximizes their contribution to the company's strategic objectives. Additionally, the managers who were persistent in rotating jobs when dealing with various COFP jobs reflect another form of integration by gradually exposing the team members to unfamiliar domains. Over time, 'this practice increases the collective understanding of the activity' (a resource planner at Build). To be more integrative as individual integrators, top managers seem to apply project-based reward systems. This practice 'recognises the [COFP] offers that have been smartly prepared' (a project manager at Build).

Regarding CFTs, two integrative aspects were identified. One aspect is the co-location and alignment of team members. 'The nearer [COFP] team members are to each other, the smoother it is to detect and resolve cross-functional conflicts' (a project manager at Build). Moreover, 'the feedback from several members of previous teams confirmed that the cross-functional learning experience improved in settings with fewer members and more diversity in terms of seniority, hierarchical and functional positions, specialist and commercial backgrounds, and roles and responsibilities' (the head of marketing at $3 \mathrm{PL}$ ).

As for task design, four aspects were found to be integrative. 'Tasks embedding problems and calling for opinions from various functions seem to be more engaging than tasks with less inclusive problems' (a resource planning manager at Aero). Another aspect is the degree of information completeness prior task execution. 'Triggering any communication across the [COFP] team members requires a minimum amount of information that allows for more calculation and less speculation' (an S\&OP analyst at Auto). 'Lacking basic specifications about core elements encourages the [COFP] team members to prioritise other tasks' (a S\&OP coordinator at Aero). 'Incomplete task-related information is often attributed to customers not being completely clear about their requests' (a production manager at Build). In addition to information completeness, task cohesion was also found to be integrative. 'Completing tasks related to design and production requires a deep knowledge of very specific areas and good knowledge of more comprehensive areas. Tasks demanding both perspectives allow for gaining balanced experience that increases the ability of the [COFP] team 


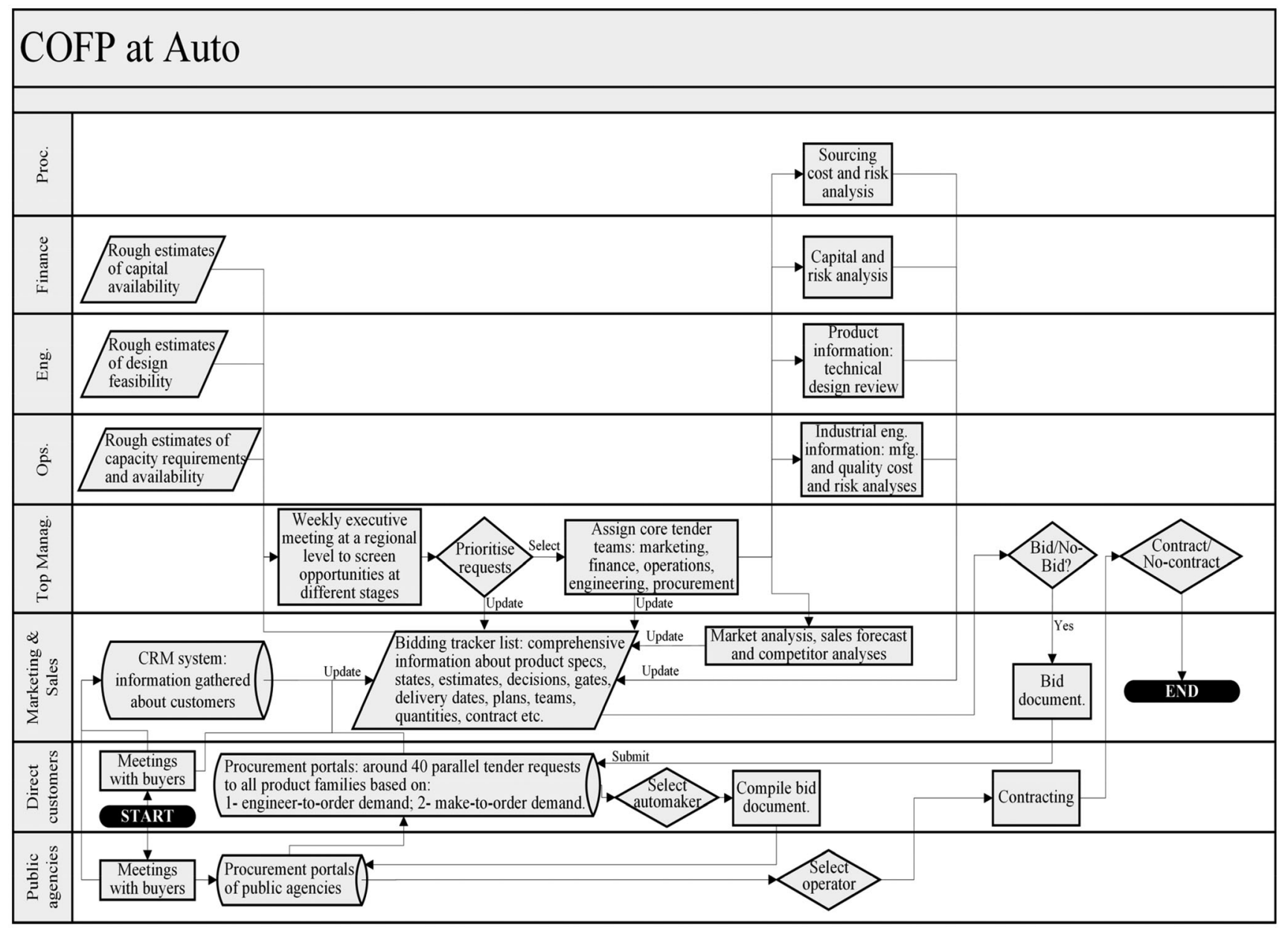

Figure 6. Cross-functional interactions within COFP at Auto.

members to be assigned in other positions in the future' (a production development manager at Build). Apart from that, the concurrency between design and production tasks was found to be integrative. 'We try to bring production onboard as early as possible along the [COFP] to allow for quicker and more accurate estimation of costs and delivery dates', stated the head of marketing at 3PL.

Table 3 incorporates three integrative forms of ISs that were captured. One fundamental but rather basic form is concerned with the support of data management infrastructure. Servers and databases were found to be integrative when they enable seamless storing and retrieval of information through, for instance, providing companywide information technology (IT) services (e.g. e-mails, teleconferences and telephones), applications (e.g. word processing and spreadsheets), and web-based gateways to collect, organize, and transmit relevant information. Apart from that, building IT tools towards customers was also found to be integrative, which is evident from the customer relationship management (CRM) software that is used in some cases that try to be more integrated into the customer order databases. Finally, using IT platforms on which product functionalities are visualized and optimized were found to be highly integrative as these tools are highly engaging, assuming that they provide a collectively perceivable reference for all functions, suppliers, and customers to build on' (a project manager at Build).

\subsection{Cross-case analysis}

The following sections describe the cross-case results shown in Table 3. Inferring from similarities and differences, section 4.2.1 describes how coordination supports decision making upon order screening and review, whereas section 4.2.2 describes how coordination supports problem-solving upon order customization and workload analysis. Where the results show that not all cases apply a form of integrative coordination mechanism, the sections provide evidence-based elicitations describing the contextual influence in shaping the need for CFI.

\subsubsection{Mechanisms to support decision making in order screening and review}

When decisions are made in the stages of order screening and review, several forms of integrative coordination related to centralization, standardization, formalization, individual integrators and $I S$ s are identified.

$3 \mathrm{PL}$, Aero, and Auto set clear and specific strategic objectives to centralize the selections of enquiries and team 
Table 3. Identified integrative mechanisms.

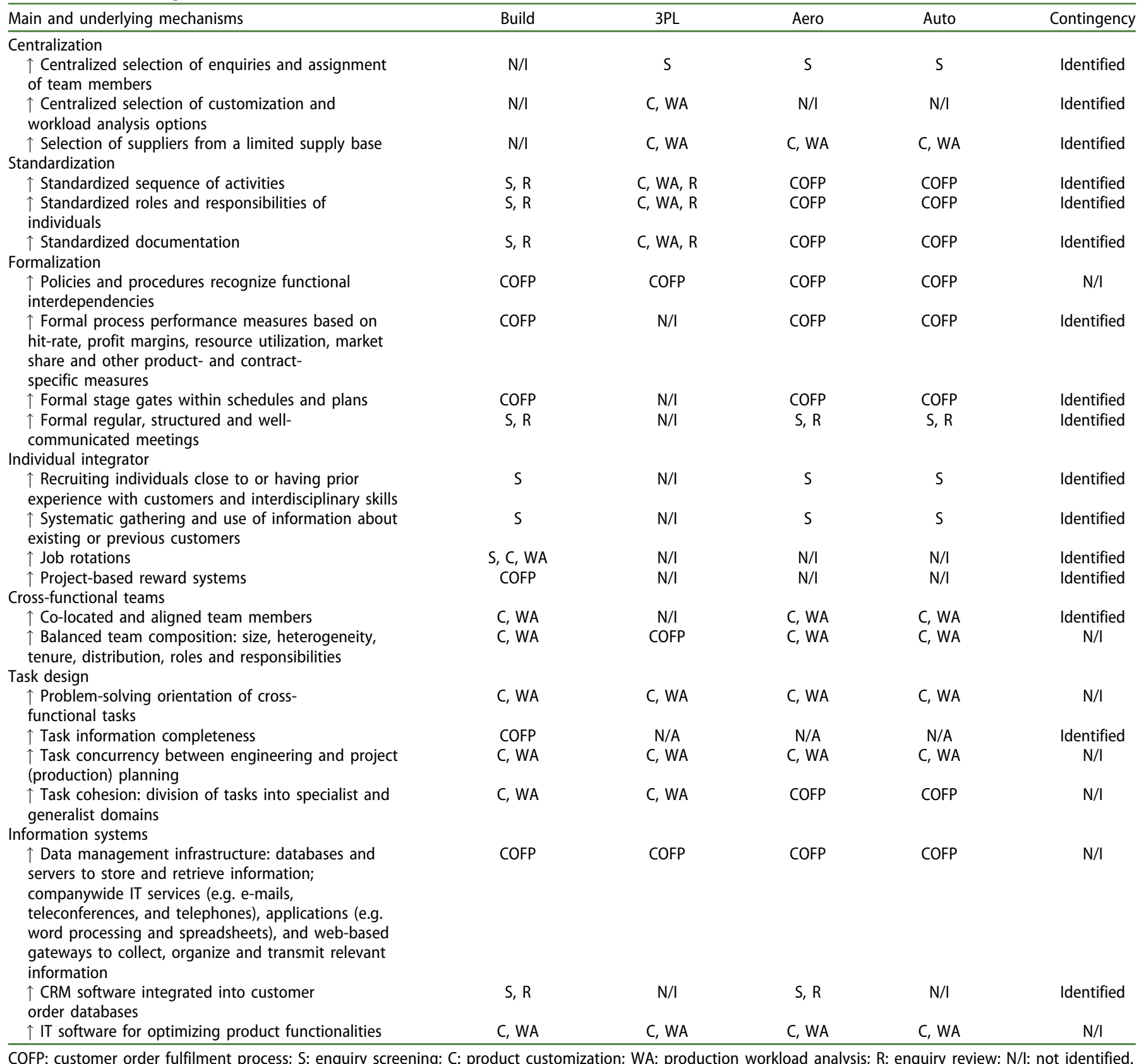

members, while the strategic objectives at Build are kept general and limited to simple figures of growth. Acting as a general contractor, Build has much broader customization scope related to product architecture, which means that the variability of product specifications is high in a way that hinders establishing specific strategic directions towards the market. Clear and specific strategic objectives help in more smoothly reaching consensus and excluding undesirable enquiries during meetings, which reduce the demand detail, represented by fewer parallel enquiries.

$3 \mathrm{PL}$, Aero, and Auto tend to assign highly ranked business development representatives to direct order screening and review and, thus, ensure the strategic alignment of order prioritization. Assigning experts knowledgeable in market dynamics as gatekeepers for order selection narrows the boundaries of cross-functional debates. This process limits the overall cross-functional communication (i.e. the supply detail in terms of the total manhours assigned to scan and review orders) to focused discussions and minimizes the demand-related uncertainty in terms of hit-rates.

Build, Aero, and Auto have standard activities, responsibilities, and documentation in the enquiry screening and review stages. At $3 \mathrm{PL}$, the top management organization involved in screening and reviewing is much smaller, which makes spreading best practices less demanding in terms of standardization. Build, Aero, and Auto have more hierarchical layers to govern operations around the globe, and such standardization seems to be an efficient practice to reduce the uncertainty concerning demand prioritization. 
All the case companies emphasize the crucial role of policies recognizing the functional interdependencies between departments. These formal statements point at which departments to involve and when the accumulated information across functions becomes enough to trigger the respective assessments. Here, a contrast, between Build, Aero, and Auto on one side, and 3PL on the opposite side, exists. The number of functions involved in order screening is greater at Build, Aero, and Auto than at 3PL. The broader scope of customizable product architecture targeted by Build, Aero, and Auto leads to more supply detail in terms of cross-functional interdisciplinarity.

Build, Aero, and Auto hold a regular formal cross-functional meeting to scan enquiries and review the prepared offers, unlike $3 \mathrm{PL}$ that conducts informal meetings when parallel enquiries arrive. Given that Build, Aero, and Auto need to assess more parallel enquiries than $3 \mathrm{PL}$, formalizing such assessment meetings is necessary for ETO settings with high demand detail. A higher meeting frequency means more dedicated manhours. More frequent assessments are important for Build due to the lack of reliable product-specific forecasts to use and aggregate at a product-family level, whereas Aero, which has the fewest customers, has the lowest frequency of such meetings. Aero has the longest periods allowed for offer preparation compared to the other cases.

Due to the high detail complexity in the cross-function communications, such as many design artefacts and many requirement specifications, Build strives to automate the information flows concerned with order selection. Unlike 3PL, Aero, and Auto that need to manually capture opportunities through personal relationships with customers or even the customers of customers (as the case for Auto), Build can integrate its CRM system into a national database through which many new enquiries originate. Build receives automatic notifications whenever an enquiry appears on the database. Moreover, the CRM software at Build has algorithms to analyse customers (based on previous experience) and competitiveness (based on previous success with similar projects and the profiles of competitors). Not only enables such automation marketing and sales to focus on demand validation instead of generation, but also ensures the relevance of all enquiries upon screening.

ISs alone are not capable of handling demand-related uncertainty such as hit-rates and demand variability, and much responsibility lies on individual integrators. Integrators are leaders who coordinate working relationships. At Build, integrators are key account managers within the COFP and site managers during project execution. Since learning about customers helps to minimize demand-related uncertainty (e.g. future product specifications and sizes), integrators at Build tend to highly utilize opportunities to gather more information about their customers. Examples can be approaching customers in fairs or similar events, or even seeking new recruitments with relevant experience from existing or potential customers. At Aero, since a few customers exist, the marketing function dedicates customer-specific teams that follow customer updates and distribute Aero's updates within the customers' large organizations. However, 3PL and Auto have the possibility of using forecasts due to having limited scopes of customizable product architecture, which means that they gather less customer information. Yet, Build, 3PL, and Auto gather fundamental information about existing customers, such as the number of change requests, strategic investment plans, and financial ability, while Aero has very few customers to consider. Integrators also play a key role in cost-effectively gathering valid information. Arguably, learning more about customers brings clarity into demand variability, which decreases demand-related uncertainty, and increases demand detail since insights into future investments needs further processing.

Although integrators have a crucial role in controlling team performance, all the interviewees agreed that basing the companywide rewarding on project performance (as in the case for Build) encourages the members of COFP teams to contribute to the COFP instead of consistently prioritizing their departmental tasks. The low commitment of functional representatives makes integrators struggle to unveil the required cross-departmental perspectives within order selection. According to all the interviewees, involving key functional representatives in common interactive platforms enables the processing of more detail compared to involving fewer departments alternately in more occasions.

The rationalization of the recruitment and assignment of CFT members that need to develop solutions and provide estimates is also crucial for integrators to consider. Build prioritizes competencies with interdisciplinary skills to enable job rotations. For instance, construction engineers may work as surveyors or buyers, which allows for processing more demand detail. However, 3PL, Aero, and Auto do not need such recruitment approaches because of the lower demandrelated uncertainty stemming from the lower specification uniqueness across enquiries, which keeps the boundaries of roles and responsibilities clear.

\subsubsection{Mechanisms to support problem-solving in custom- ization \& workload analysis}

As orders proceed to customization and workload analysis, the main activity changes from rationalizing order selection to generating solutions for respective design and production. In these stages, several integrative coordination practices related to centralization, standardization, formalization, CFTs, task design, and ISs were observed.

All cases dedicate CFTs but vary when it comes to co-location and team composition. By enabling physical reach and intensifying face-to-face interactions, CFTs at Build, Aero, and Auto more quickly detect and minimize conflicts, leading to less supply-related uncertainty. Co-location provides communication transparency and frequency, making the need for reliable competencies less demanding, which unlocks some constraints. However, the co-location of CFT members at 3PL is not prioritized over having the core team members along with the project manager located near project locations.

In all four cases, the CFT composition determines the maximum performance capacity. Thus, considering the team size and heterogeneity, members should be allocated so that to maximize the performance of all teams. Team sizes for 
customization and workload analysis should be small to simplify coordination, while balanced team heterogeneity enables the collective performance to match the required productivity level of all teams. For instance, balancing the experience-based heterogeneity (i.e. the distribution of experienced members) across all teams allows for synergies in the collective capacity, which enables processing more demand detail. Effective distribution entails matching experienced members with the most uncertain enquiries to maximize their utilization.

Another example is the heterogeneity of age and tenure. The cases show that proper distribution of age and tenure across teams minimizes the impact of absenteeism on capacity as novices become, due to higher exposure, more prepared to back up experts.

Upon order customization and workload analysis, Aero, Auto, and 3PL have standard activities, responsibilities, and documentation, while Build has a broader scope of customizable product architecture, which calls for tackling more heterogeneity in customer needs, products, and parts. Build is in greater need of low volume production, which challenges standardization. That is, at Build, the alternative activity sequences, documentation standards, and team roles and responsibilities are enormous and dependent on the type of products, customers, and suppliers involved. Such variability limits the possibility of finding standard best practices.

As for centralization, at $3 \mathrm{PL}$, marketing and top management direct technical decisions associated with customization and workload analysis due to having lower demand detail in terms of parallel inquiries. 3PL, Aero, and Auto have more limited scope of customizable product architecture, less variability of enquiry budgets, smaller products, and fewer product parts than Build. Consequently, 3PL, Aero, and Auto need smaller organizations and fewer functions, which enabled integration at the enterprise level. Here, the substitutability of reliable resources across roles is low since the boundaries across distinct roles and functions are clearer than in Build. Accordingly, the departments actively cooperate, not necessarily through CFTs. Such tight hierarchical integration reduces the uncertainty stemming from internal resource reliability, which is a challenge for Build.

In contrast to the other cases, the customization and workload analysis activities at Build are decentralized to some extent. Here, the autonomy of CFTs is necessary to ensure work satisfaction as Build deals with a broad scope of customizable product architecture, high variability of enquiry budgets, large products, and many parts and modules. Nevertheless, when the organization concerned with a particular discipline grows in size (i.e. more supply detail), centralization becomes necessary to structure the respective contributions. A simple example is to delegate design-specific decisions to a design leader.

An interplay between the scope and breadth of customizable product architecture, the availability of internal resources, and the number of external contributors is noted. At Build, centralizing expanding disciplines increases the availability of internal resources by being allocated as engineering coordinators while outsourcing the actual engineering work.

$3 \mathrm{PL}$, Aero, and Auto centralize procurement through establishing long-term relationships with far fewer suppliers than in Build. Through supplier-buyer system integration, 3PL, Aero, and Auto reciprocate confidential information and artefacts with their suppliers to gain access to inventories, availabilities, costs, and mutual communication platforms. Not only reduces such integration the required supply coordination (i.e. the detail complexity), but it also speeds up the validation process, leading to less uncertainty.

At Build, establishing long-term relationships with fewer suppliers is not a viable option since site managers (a critical competency) demand the freedom to select suppliers. The short-term and geographically exclusive relationships broaden the supply base and the overall variability in supplier lead time, which entails more detail and uncertainty.

Build, Aero, and Auto dedicate formal structured problemsolving task instructions, process descriptions, requirements, standards, guidelines, and other similar types of information. Instructional information provided at the commencement of teamwork addresses task objectives, milestones, and key dates to guide the expectations of interdependent functions in terms of deliverables and respective timings. Such formalization minimizes confusion and increases consistency across enquiries, which minimizes reworks and delays and, thus, increases the availability and reliability of internal resources. The absence of such formalization at 3PL is due to its smaller organization.

Concerning task design, several aspects are observed: task problem-solving orientation, concurrency, and cohesion. The tasks of customization and workload analysis at all cases are highly problem-solving oriented, which needs multi-variable scenario-based analyses to minimize lead times and costs and optimize product functionalities.

At all the case companies, concurrency offers time savings. For example, by establishing validating iterations between design and production specialists at the component instead of product level, the development time diminishes since production specialists can instantly start the work associated with the approved components, which increases the internal resource utilization. As the cases confirmed, a positive integrative impact on the effect of other mechanisms, e.g. the explicit recognition of cross-functional inter-dependencies and co-location, came into play when task concurrency increased.

Regarding task cohesion, in all the cases, both generalist and specialist domains are combined within individual tasks. Specialist tasks require special knowledge related to an area, while generalist tasks require leadership and understanding of several areas. Such division facilitates the matching process of available human capital and minimizes delays as tasks become less dependent on individuals. All the cases ensure cohesion by enhancing the specialists' interdisciplinary knowledge and leadership skills as generalists are strategically important to win customer orders.

Performing tasks depends on information. At Build, customer input (project briefs) varies in terms of information 
completeness, which influences the task design. Seniors analyse the gaps in customer inputs following a certain order of accumulating relevant information from various sources; that is, the order of task assignment and member involvement matters. 3PL, Aero, and Auto do not adopt this approach since their customers are specific about their preferences. Planning information gathering from internal and external sources in logical orders is still important to minimize the task-related uncertainty.

Finally, the cases show the importance of IT systems that enable the modelling and simulation of product functionalities and production processes. Such tools provide insights into the qualities and delivery costs in many scenarios. Moreover, these (often visualized) models facilitate smoother and more detailed feedback about strengths, weaknesses, and alternative solutions between stakeholders, which enables absorbing more demand detail.

\section{Discussion}

DS balancing is a crucial capability for each actor in the SC to ensure stability and minimize the amplification of the so-called bullwhip effect (Lee, Padmanabhan, and Whang 1997). Towards this end, this study identifies key CFI mechanisms applied in the COFP to increase the understanding for how CFI mitigates the negative complexity impact in terms of detail and uncertainty on DS balancing in ETO settings.

Findings suggest several CFI mechanisms, some of which seem to be generally transferable to other ETO settings, while the impact of the other mechanisms on DS balancing seems to be driven by some contextual factors. Due to this study being explorative, future research may further investigate the validity of the transferable mechanisms and provide insights into the contingencies underlying the other mechanisms.

All the cases adopt seven CFI practices that can be transferable, two of which apply to the whole COFP, while the other practices apply to customization and workload analysis. All the cases reflect substantial cross-functional interdependences, which is congruent with the generic ETO characteristics (Gosling and Naim 2009; Mello, Strandhagen, and Alfnes 2015). Therefore, to reduce the uncertainty about the sequence of interactions and delimit the detail of underlying content, the cases dedicate formal policies and procedures recognizing the sequential interdependencies between functions as rules of inference for order assessment. Oliva and Watson (2011) claim the planning procedural quality increases when the rules of inference driving the decisionmaking activities ensure information validity. Accordingly, the study suggests the following proposition:

P1: In ETO environments, formalising the sequence specifying when each function needs to perform decision-making activities and delineating the boundaries of underlying assessments to maximise information validity increase the planning procedural quality.

Since ETO businesses allow for customization, involving large engineering entities is typical in the COFP compared to other environments, like MTO and MTS settings (Hicks, McGovern, and Earl 2000). High performing companies should consider how to achieve seamless information dissemination and how to identify and share key information in new product development (NPD) (Galbraith 1977; Troy, Hirunyawipada, and Paswan 2008), which is a natural part of the regular engineering within the COFP in ETO settings (Gosling and Naim 2009). Such engineering-intensive crossfunctional interactions demand seamless companywide and real-time contributions to enable efficient reviewing of design artefacts and processing of interdepartmental requirements. Expectedly, each case uses a variety of ISs striving to seamlessly store, retrieve, collect, organize, and transmit data across functions. For instance, in line with Sherman, Berkowitz, and Souder (2005) and Kahn (1996), cases ensure routines in the COFP for utilizing the data from previous projects to guide the execution of similar tasks related to current and future projects. For Fernández Campos, Trucco, and Huaccho Huatuco (2019), ISs capable of efficiently processing abundant demand- and supply-related data and enquiries about specific uncertainty increase the complexityabsorptive capacity. Hence, this study suggests the following:

P2: In ETO environments, data management infrastructures capable of seamless inter-departmental storing, retrieving, collecting, organising, and transmission of data enable the COFP to absorb greater demand and supply detail and related uncertainty.

Under customization and workload analysis, findings suggest five CFI practices that enable ETO companies to process more detailed and uncertain demand by resolving more detailed and uncertain supply capacity: balancing of CFT composition, problem-oriented tasks, task concurrency, task cohesion, and IT modelling and simulation systems.

According to Holland, Gaston, and Gomes (2000) and Mathieu et al. (2014), balancing CFTs' composition, in terms of size and heterogeneity, drives the success of NPD activities. This also applies to the COFP having similar integrated engineering and production settings (Mello, Strandhagen, and Alfnes 2015). Unsurprisingly, in the COFP, the cases rely on CFTs to assess incoming orders and prepare bid documents. To minimize the sizes of CFTs, the cases assign project managers to individual enquiries, who coordinate small core teams, which involve one key representative from marketing, sales, production, and finance. CFTs involve some crucial and often rare competencies, which require long qualification periods. Cooper and Budd (2007) confirmed the rareness of such competencies that are fundamental to win contracts and that CFTs are common in ETO settings. Therefore, the cases try to maximize the overall output of their CFTs by ensuring a balanced distribution of experience, age, and tenure over the teams. By increasing such heterogeneity, the cases can form more eligible CFTs that fulfil the prerequisites to process customer enquiries. As such, the study sets forth the following proposition:

P3: In ETO markets driven by tendering, forming small sized CFTs with heterogeneous compositions that ensure wide ranges of experience, age, and tenure among members in each team enables processing greater demand detail and related uncertainty.

Designing tasks has a coordination effect (Holland, Gaston, and Gomes 2000; Hirunyawipada, Beyerlein, and 
Blankson 2010). Findings confirm the need to consider three dimensions when designing a task: problem-solving orientation, concurrency, and cohesion. According to Daugherty, Stank, and Rogers (1992), setting clear problem objectives as task drivers dissolves the uncertainty concerning which functions should execute a task. The tasks within customization and workload analysis focus on minimizing lead times and costs and optimizing product functionalities. As such, this study puts forward the following:

P4: In ETO environments, setting clear problem objectives for tasks upon order customisation and workload analysis reduces the supply-related uncertainty associated with the underlying cross-functional interdependence.

As for task concurrency, Sherman, Berkowitz, and Souder (2005) suggest that increasing information flows between $R \& D$ and manufacturing when designing a product reduces later design changes and leads to more simple designs and standard assemblies and components that are cost effective from a manufacturing's perspective. Departing from the complexity management logic of Fernández Campos, Trucco, and Huaccho Huatuco (2019), task concurrency, thus, serves as a complexity-absorbing practice allowing for processing more demand detail and related uncertainty. Findings confirm that this proposition applies to customization and workload analysis. This is because the periods between the enquiry announcements and the offering submission deadlines are short, considering the intensity of the engineering work required to produce reliable cost and duration estimates and develop delivery plans (Cooper and Budd 2007).

In a broad sense, time compression is a key design and operation principle in ETO environments (Gosling et al. 2015). Therefore, the cases show that hitting the offering deadlines is difficult without implementing concurrency, at least between product design and manufacturing engineering activities, identifying when each function can start executing tasks in parallel with other ongoing tasks so as to compress the lead time of customization and workload analysis. Previous studies also stressed such concurrency benefits in less complex environments (Turkulainen and Ketokivi 2012). Moreover, parallelizing cross-functional tasks increases the validation quality during meetings as more participants become keener to actively contribute due to gaining familiarity with their tasks and the overall background prior the meetings, which entails less uncertainty (Oliva and Watson 2011). Accordingly, this study suggests the following proposition:

P5: Upon order customisation and workload analysis in ETO environments, effective task concurrency between demand- and supply-facing functions enables processing greater demand detail and related uncertainty within shorter periods.

Hirunyawipada, Beyerlein, and Blankson (2010) suggest task cohesion as an effective CFI mechanism in NPD settings. Consistently, to perform tasks within customization and workload analysis, the cases either assign generalists, who understand relationships between many areas, or specialists, who are knowledgeable more deeply in a few areas. Findings show that task cohesion unlocks internal resource availability as tasks become dependent on less individuals.
Whether ETO companies are vertically integrated, specialized in design and assembly or design and contract, or driven by pure project management organizations, work domains where customization applies keep on growing and maturing due to the upgrading and integrating potentials embedded at the component level of ETO products (Hicks, McGovern, and Earl 2001). Consequently, new specialized domains evolve and grow, calling for generalists that set standards and organize the corresponding workflows. Similarly, the cases ensure task cohesion by promoting the specialists' interdisciplinary knowledge and leadership skills as generalists are key to outperform their rivals. Accordingly, the study sets forth the following proposition:

P6: Upon order customisation and workload analysis in ETO environments, dividing tasks into generalist and specialist domains to enhance task cohesion increases the complexityabsorptive capacity of processing demand detail and related uncertainty.

According to Fernández Campos, Trucco, and Huaccho Huatuco (2019), ISs supporting decision making and knowledge generation do mitigate the negative impact of supplyrelated dynamic complexity on SC performance. In line with this, limited integration literature (e.g. Sherman, Berkowitz, and Souder 2005; Troy, Hirunyawipada, and Paswan 2008) emphasizes the integrative role of IS capability in optimizing product functionalities and serving as a platform to test solutions in problem-solving activities, which are, as evidenced from the cases, similar to the characteristics of customization and workload analysis. In a broad sense, information transparency is a key design and operations principle in ETO environments (Gosling et al. 2015). Towards this end, the cases rely on IT tools to model and simulate product functionalities and production processes as to ensure quick and consistent approaches to generate cost-effective solutions and requirements given many scenarios. Findings confirm that the (often visualized) IT models enable processing greater demand detail and related uncertainty by facilitating smooth and detailed feedback about strengths, weaknesses, and alternative solutions between functions. As such, this study sets forth the following proposition:

P7: Upon order customisation and workload analysis in ETO environments, using ISs supporting the modelling and optimisation of product functionalities and the consequent production processes increases the complexity-absorptive capacity of processing demand detail and related uncertainty.

Other CFI mechanisms may under certain contextual settings positively influence the complexity that negatively influences DS balancing. Table 4 presents more detail about the contextual (or contingency) configurations identified in this study. That is, contextual settings representing high or low values of contextual variables may have a moderating effect on the relationship between the CFI mechanisms and the complexity variables affecting DS balancing. For instance, standardizing activities, responsibilities, and documentation upon order screening and review; formalizing process performance measures and planning stage gates; and ensuring co-location of CFTs seem to effectively reduce or absorb 
Table 4. Contextual configurations driving the effectiveness of some CFI mechanisms.

\begin{tabular}{|c|c|c|}
\hline Mechanism(s) & No or low contextual effect on complexity & Noticeable contextual effect on complexity \\
\hline $\begin{array}{l}\text { - Centralized selection of order and } \\
\text { CFT members } \\
\text { - Formal regular, structured and well- } \\
\text { communicated meetings upon order screening } \\
\text { and review }\end{array}$ & Late decoupling: Most engineering to forecast & $\begin{array}{l}\text { Early decoupling: Most engineering after } \\
\quad \text { order entry }\end{array}$ \\
\hline $\begin{array}{l}\text { - Task information completeness } \\
\text { - Task cohesion upon order screening } \\
\text { and review }\end{array}$ & Early decoupling: Most engineering after order entry & Late decoupling: Most engineering to forecast \\
\hline $\begin{array}{l}\text { - Centralized selection of customization and } \\
\text { workload options } \\
\text { - Balanced CFT composition upon order } \\
\text { screening and reivew }\end{array}$ & $\begin{array}{l}\text { Organizational size: Large } \\
\text { Number of parallel orders: Many }\end{array}$ & $\begin{array}{l}\text { Organizational size: Small or medium } \\
\text { Number of parallel orders: Limited }\end{array}$ \\
\hline $\begin{array}{l}\text { - Standard activities, roles and responsibilities, } \\
\text { and documentation upon order screening } \\
\text { and review } \\
\text { - Formal process performance measures and } \\
\text { planning stage gates } \\
\text { - Co-location of CFTs }\end{array}$ & Organizational size: Small or medium & Organizational size: Large \\
\hline $\begin{array}{l}\text { Ird activities, roles and responsibilities } \\
\text { cumentation upon order customization }\end{array}$ & Scope of customizable product architecture: Broad & $\begin{array}{l}\text { Scope of customiz } \\
\text { architecture: Lir }\end{array}$ \\
\hline $\begin{array}{l}\text { Recruiting individuals close to or having prior } \\
\text { experience with customers and } \\
\text { interdisciplinary skills }\end{array}$ & Limited & Scope of customizable product architecture: Broad \\
\hline $\begin{array}{l}\text { - Automated data collection about } \\
\text { customer orders }\end{array}$ & Platforms or databases for offerings: Decentralized & Platforms or databases for offerings: Centralized \\
\hline $\begin{array}{l}\text { - Systematic gathering and use of information } \\
\text { about existing or previous customers }\end{array}$ & Limited engineering to forecast or limited customers & $\begin{array}{l}\text { Mostly engineering to forecast and } \\
\text { many customers }\end{array}$ \\
\hline - Project-based reward systems & Organizational st & Organizational structure: Mostly project-b \\
\hline - Job rotations & Ratio of generalist to specialist professions: Low & Ratio of generalist to specialist professions: High \\
\hline $\begin{array}{l}\text { - Centralized selection of suppliers from a } \\
\text { limited supply base }\end{array}$ & delivery addresses & $\begin{array}{l}\text { Assembly location: mostly at established } \\
\text { manufacturing facilities }\end{array}$ \\
\hline
\end{tabular}

complexity when interactions occur within larger organizations that have more engineering functions.

The study does not comprehensively cover all forms of mechanisms relevant to ETO settings. For instance, other forms of coordination mechanisms, such as modularization (a form of standardization), were not observed in the selected cases, but these were addressed in previous studies as mass customization enablers for transitioning to less complex settings like MTO and Assemble-to-Order (ATO) settings (e.g. Vellmar, Gepp, and Schertl 2017). Moreover, other forms might be more relevant to standardized settings. For instance, automating information processing of certain crossfunctional interactions like customer order acceptance seems to be applicable in some MTS settings, given the states of finished-goods inventories (Vidoni and Vecchietti 2015).

\section{Concluding remarks}

\subsection{Contributions to theory and practice}

This study offers a comprehensive review of the CFI (coordination) practices applied in the COFP in four ETO-oriented companies to manage the complexity stemming from demand and supply. The complexity logic of Senge (1998), combined with the perspective of Serdarasan (2013) about uncertainty being the essence of dynamic complexity, provides a simplified normative approach for analysing the complexity embedded in a certain domain. Previous literature separately addressed how to manage complexity (e.g. Fernández Campos, Trucco, and Huaccho Huatuco 2019) and how CFI can be effective in improving performance (e.g. Turkulainen and Ketokivi 2012). Given the suggested propositions, this study links both areas by studying how CFI mitigates the negative impact of complexity on DS balancing, which is inspiring for other CFI-driven processes like S\&OP that share the same objective (Oliva and Watson 2011).

Instead of discussing coordination as high-level practices with the same impact on complexity, as done by Fernández Campos, Trucco, and Huaccho Huatuco (2019), the propositions introduce additional granularity in terms of mechanisms. The descriptions regarding how coordination manages complexity provides insights that enrich or complement findings from previous works that explain the coordination mechanisms generated by S\&OP (e.g. Tuomikangas and Kaipia 2014) or those investigating how to improve coordination in ETO settings (e.g. Mello, Strandhagen, and Alfnes 2015).

Conceptually, this study proposes another perspective on relating relevant constructs to integration. Integration was conceptualized using the resource-dependency theory and the information-processing theory (Galbraith 1977). The latter is the basis for the research to which this study contributes. Instead of viewing integration as either interactions or collaborations, as suggested by Kahn (1996), coordination is fused into integration as a relevant construct, and interactions are viewed as mere reciprocal actions that signal the state of coordination or collaboration.

The study findings practically imply that companies may not necessarily use one mechanism to integrate functions together or into customers and suppliers as contextual factors seem to drive why and how each of the four cases apply CFI mechanisms. The study suggests several related contextual factors that drive the impact of several CFI mechanisms on complexity. Together with the study propositions, such 
contingency insights guide practitioners in ETO-oriented settings in identifying effective approaches and help to anticipate the impact of their decisions. This eventually assists in shaping suitable integration strategies and investments, considering the growing demand- and supply-driven complexity. For instance, as can be inferred from the propositions, if the desired strategy is to be more demand responsive (i.e. to offer greater flexibility), practitioners may allow for greater demand detail and related uncertainty, thereby calling for CFI mechanisms with a balancing and absorbing impact on supply detail and related uncertainty.

\subsection{Limitations and future research}

Some limitations do exist. While case studies are appropriate methods in theory building (Eisenhardt 1989), future quantitative research testing the study propositions may ensure their generalizability.

The selected cases represent various configurations of complexity (Figure 2), which are a basis to understand the similarities and differences between them in terms of the CFI mechanisms applied. Another approach to consider is to analytically use such configurations by studying the contingency of the mechanisms suggested in Table 3 on the negative impact of complexity on DS balancing in line with Sousa and Voss (2008), as contingency research on tactical planning has received attention in the last decade (see Kristensen and Jonsson 2018). Such research may provide insights into how changes in the value of certain variables, such as the firm size, moderates the effect of certain coordination mechanisms on the negative impact of complexity. Addressing additional ETO cases which entail greater variety in cross-case complexity would complement and validate the generated contingency insights.

As discussed earlier, this study recognizes collaboration as a relevant construct for integration but does not address it as part of the scope. Collaboration includes subjective aspects such as trust and mutual understanding (Kahn 1996). Arguably, capturing empirical evidence for such collaboration mechanisms requires different analytical logics from what this study adopts, which are more straightforward. Therefore, to complement the study's findings and build a more comprehensive understanding of $\mathrm{CFI}$, future research should focus on the collaboration dimension using a qualitative method. Collaboration is debatably less explored as an integrative mechanism compared to coordination.

The unit of analysis in this study is the COFP. Previous research claims that CFI occurs when information among demand- and supply-facing departments is shared and exploited (Troy, Hirunyawipada, and Paswan 2008). This may apply to other processes than the COFP. For instance, S\&OP is a CFI-driven process for demand and supply planning (e.g. Oliva and Watson 2011) and, thus, can be the unit of analysis in future studies.

Finally, while the findings cover several coordination mechanisms, future research should focus on deepening the understanding of the forms and impacts of individual mechanisms. Such efforts will enrich and refine the study's findings, leading to greater granularity and validity.

\section{Disclosure statement}

No potential conflict of interest was by reported the author(s).

\section{Notes on contributors}

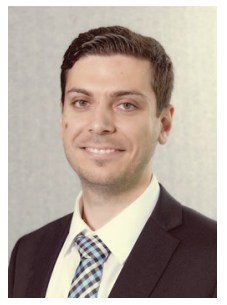

Hafez Shurrab holds a degree of licentiate of engineering. He studies the demand-supply balancing effect of tactical-level planning processes, focussing on three interfaces in complex settings. For the strategic-tactical interface, the focus is on customer order fulfilment, while for the tactical interface, the focus is on sales and operations planning. Both interfaces address engineer-to-order markets. For the tactical-operational interface, the focus is on the schedule instability of automakers.

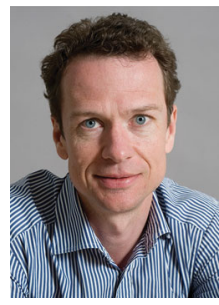

Patrik Jonsson is a professor of Operations and Supply Chain Management at Chalmers University of Technology. He gained his Ph.D. in production management from Lund University. His research interests are in the field of operations and supply chain planning, with a specific interest in the generation of demand and supply coordination in firms and supply chains through data- and technology-enabled operations and planning processes (e.g. demand management and sales and operations planning).

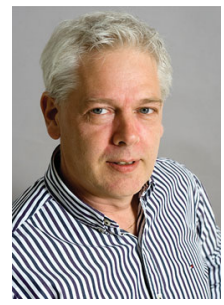

Mats I. Johansson is professor in logistics and supply chain management at the Department of Technology Management and Economics, Chalmers University of Technology, Sweden. He holds a MSc in Mechanical Engineering and received a PhD in Transportation and logistics (1989) within the area of logistics and product design, focussing logistic performance in mixed-model production environments. His research interests include development, planning and control of materials supply and distribution systems, including their supporting information systems and methods for evaluating competitiveness and resource consumption.

\section{ORCID}

Hafez Shurrab (ID) http://orcid.org/0000-0002-6897-7227

Patrik Jonsson (iD http://orcid.org/0000-0002-9457-5854

Mats I. Johansson (D) http://orcid.org/0000-0001-5074-1737

\section{References}

Barratt, M., T. Y. Choi, and M. Li. 2011. "Qualitative Case Studies in Operations Management: Trends, Research Outcomes, and Future Research Implications." Journal of Operations Management 29 (4): 329-342. doi:10.1016/j.jom.2010.06.002.

Berry, W. L., T. E. Vollmann, D. C. Whybark, and F. R. Jacobs. 2011 Manufacturing Planning and Control for Supply Chain Management. New York, NY: McGraw Hill.

Birkie, S. E., and P. Trucco. 2016. "Understanding Dynamism and Complexity Factors in Engineer-to-Order and Their Influence on Lean Implementation Strategy." Production Planning \& Control 27 (5): 345-359. doi:10.1080/09537287.2015.1127446.

Bozarth, C. C., D. P. Warsing, B. B. Flynn, and E. J. Flynn. 2009. "The Impact of Supply Chain Complexity on Manufacturing Plant 
Performance." Journal of Operations Management 27 (1): 78-93. doi: 10.1016/j.jom.2008.07.003.

Carvalho, A. N., F. Oliveira, and L. F. Scavarda. 2015. "Tactical Capacity Planning in a Real-World ETO Industry Case: An Action Research." International Journal of Production Economics 167 (2015): 187-203. doi:10.1016/j.ijpe.2015.05.032.

Chen, F., Z. Drezner, J. K. Ryan, and D. Simchi-Levi. 2000. "Quantifying the Bullwhip Effect in a Simple Supply Chain: The Impact of Forecasting, Lead Times, and Information." Management Science 46 (3): 436-443. doi:10.1287/mnsc.46.3.436.12069.

Cho, J., and J. Kang. 2001. "Benefits and Challenges of Global Sourcing: Perceptions of US Apparel Retail Firms." International Marketing Review 18 (5): 542-561. doi:10.1108/EUM0000000006045.

Chow, G., T. D. Heaver, and L. E. Henriksson. 1995. "Strategy, Structure and Performance: A Framework for Logistics Research." Logistics and Transportation Review 31 (4): 285.

Closs, D. J., M. A. Jacobs, M. Swink, and G. S. Webb. 2008. "Toward a Theory of Competencies for the Management of Product Complexity: six Case Studies." Journal of Operations Management 26 (5): 590-610. doi:10.1016/j.jom.2007.10.003.

Combley, R. 2011. Cambridge Business English Dictionary. Cambridge: Cambridge University Press.

Cooper, M. J., and C. S. Budd. 2007. "Tying the Pieces Together: A Normative Framework for Integrating Sales and Project Operations." Industrial Marketing Management 36 (2): 173-182. doi:10.1016/j. indmarman.2006.03.005.

da Silveira, G. J. C. 2005. "Market Priorities, Manufacturing Configuration, and Business Performance: An Empirical Analysis of the OrderWinners Framework." Journal of Operations Management 23 (6): 662-675. doi:10.1016/j.jom.2005.01.005.

Daugherty, P. J., T. P. Stank, and D. S. Rogers. 1992. "The Impact of Formalization on Warehousing Firms." The International Journal of Logistics Management 3 (2): 49-62. doi:10.1108/09574099210804859.

Eisenhardt, K. M. 1989. "Building Theories from Case Study Research." Academy of Management Review 14 (4): 532-550. doi:10.5465/amr. 1989.4308385.

Fernández Campos, P., P. Trucco, and L. Huaccho Huatuco. 2019. "Managing Structural and Dynamic Complexity in Supply Chains: Insights from Four Case Studies." Production Planning \& Control 30 (8): 611-623. doi:10.1080/09537287.2018.1545952.

Galbraith, J. R. 1977. Organization Design. London: Addison-Wesley.

Gosling, J., and M. M. Naim. 2009. "Engineer-to-Order Supply Chain Management: A Literature Review and Research Agenda." International Journal of Production Economics 122 (2): 741-754. doi:10. 1016/j.ijpe.2009.07.002.

Gosling, J., D. R. Towill, M. M. Naim, and A. R. Dainty. 2015. "Principles for the Design and Operation of Engineer-to-Order Supply Chains in the Construction Sector." Production Planning \& Control 26 (3): 203-218. doi:10.1080/09537287.2014.880816.

Hicks, C., T. McGovern, and C. F. Earl. 2000. "Supply Chain Management: A Strategic Issue in Engineer to Order Manufacturing." International Journal of Production Economics 65 (2): 179-190. doi:10.1016/S09255273(99)00026-2.

Hicks, C., T. McGovern, and C. F. Earl. 2001. "A Typology of UK Engineerto-Order Companies." International Journal of Logistics Research and Applications 4 (1): 43-56. doi:10.1080/13675560110038068.

Hirunyawipada, T., M. Beyerlein, and C. Blankson. 2010. "Cross-Functional Integration as a Knowledge Transformation Mechanism: Implications for New Product Development." Industrial Marketing Management 39 (4): 650-660. doi:10.1016/j.indmarman.2009.06.003.

Holland, S., K. Gaston, and J. Gomes. 2000. "Critical Success Factors for Cross-Functional Teamwork in New Product Development." International Journal of Management Reviews 2 (3): 231-259. doi:10. 1111/1468-2370.00040.

Hsieh, H. F., and S. E. Shannon. 2005. "Three Approaches to Qualitative Content Analysis." Qualitative Health Research 15 (9): 1277-1288. doi: 10.1177/1049732305276687.

Kahn, K. B. 1996. "Interdepartmental Integration: A Definition with Implications for Product Development Performance." Journal of
Product Innovation Management 13 (2): 137-151. doi:10.1111/15405885.1320137.

Kristensen, J., and P. Jonsson. 2018. "Context-Based Sales and Operations Planning (S\&OP) Research: A Literature Review and Future Agenda." International Journal of Physical Distribution \& Logistics Management 48 (1): 19-46. doi:10.1108/IJPDLM-11-2017-0352.

Lee, H. L., V. Padmanabhan, and S. Whang. 1997. "The Bullwhip Effect in Supply Chains." Sloan Management Review 38: 93-102.

Mathieu, J. E., S. I. Tannenbaum, J. S. Donsbach, and G. M. Alliger. 2014. "A Review and Integration of Team Composition Models: Moving toward a Dynamic and Temporal Framework." Journal of Management 40 (1): 130-160. doi:10.1177/0149206313503014.

Mello, M. H., J. O. Strandhagen, and E. Alfnes. 2015. "Analyzing the Factors Affecting Coordination in Engineer-to-Order Supply Chain." International Journal of Operations \& Production Management 35 (7): 1005-1031. doi:10.1108/IJOPM-12-2013-0545.

Nihtilä, J. 1999. "R\&D-Production Integration in the Early Phases of New Product Development Projects." Journal of Engineering and Technology Management 16 (1): 55-81. doi:10.1016/S0923-4748(98)00028-9.

Olhager, J. 2010. "The Role of the Customer Order Decoupling Point in Production and Supply Chain Management." Computers in Industry 61 (9): 863-868. doi:10.1016/j.compind.2010.07.011.

Oliva, R., and N. Watson. 2011. "Cross-Functional Alignment in Supply Chain Planning: A Case Study of Sales and Operations Planning." Journal of Operations Management 29 (5): 434-448. doi:10.1016/j.jom. 2010.11.012.

Senge, P. M. 1998. "The Leader's New Work: Building Learning Organizations." In Leading Organizations: Perspectives for a New Era, edited by G. R. Hickman, 439-457. Thousand Oaks, CA: SAGE Publications.

Serdarasan, S. 2013. "A Review of Supply Chain Complexity Drivers." Computers \& Industrial Engineering 66 (3): 533-540. doi:10.1016/j.cie. 2012.12.008

Sherman, J. D., D. Berkowitz, and W. E. Souder. 2005. "New Product Development Performance and the Interaction of Cross-Functional Integration and Knowledge Management." Journal of Product Innovation Management 22 (5): 399-411. doi:10.1111/j.1540-5885.2005.00137.x.

Shurrab, H., P. Jonsson, and M. Johansson. 2020. "A Tactical DemandSupply Planning Framework to Manage Complexity in Engineer-toOrder Environments: Insights from an In-Depth Case Study." Production Planning \& Control.doi:10.1080/09537287.2020.1829147.

Sousa, R., and C. A. Voss. 2008. "Contingency Research in Operations Management Practices." Journal of Operations Management 26 (6): 697-713. doi:10.1016/j.jom.2008.06.001.

Sun, S., and J. Yen. 2005. "Information Supply Chain: A Unified Framework for Information-Sharing." Paper Presented at the Annual Meeting for the Society of Intelligence and Security Informatics, Atalanta, May 19-29. Heidelberg, Berlin: Springer.

Troy, L. C., T. Hirunyawipada, and A. K. Paswan. 2008. "Cross-Functional Integration and New Product Success: An Empirical Investigation of the Findings." Journal of Marketing 72 (6): 132-146. doi:10.1509/jmkg. 72.6.132.

Tuomikangas, N., and R. Kaipia. 2014. "A Coordination Framework for Sales and Operations Planning (S\&OP): Synthesis from the Literature." International Journal of Production Economics 154 (2014): 243-262. doi:10.1016/j.ijpe.2014.04.026.

Turkulainen, V., and M. Ketokivi. 2012. "Cross-Functional Integration and Performance: What Are the Real Benefits?" International Journal of Operations \& Production Management 32 (4): 447-467. doi:10.1108/ 01443571211223095.

Vellmar, J., M. Gepp, and A. Schertl. 2017. "The Future of Engineering Scenarios of the Future Way of Working in the Engineer-to-Order Business." Paper Presented at the Annual Meeting for the Society of IEEE International Systems Conference (SysCon), Florida, April 1-5. Piscataway, NJ: IEEE.

Vidoni, M. C., and A. R. Vecchietti. 2015. "A Systemic Approach to Define and Characterize Advanced Planning Systems (APS)." Computers \& Industrial Engineering 90 (2015): 326-338. doi:10.1016/j.cie.2015.10.006.

Voss, C., N. Tsikriktsis, and M. Frohlich. 2002. "Case Research in Operations Management." International Journal of Operations \& 
Production Management 22 (2): 195-219. doi:10.1108/ 01443570210414329.

Wikner, J., and M. Rudberg. 2005. "Integrating Production and Engineering Perspectives on the Customer Order Decoupling Point." International Journal of Operations \& Production Management 25 (7): 623-641. doi:10.1108/01443570510605072.

Yin, R. K. 2009. Case Study Research: Design and Methods. Thousand Oaks, CA: SAGE Publications.

\section{Appendix 1. Interview guide}

a. Company:

- Assertion: the company name and identity will not be used or explicated indirectly in this research. Thank you for your collaboration in advance!

- Disclaimer: the guide questions represent the starting discussion points, and the scope of the consequent discussions may become extended beyond what the questions try to directly address if other important information is identified.

- Request for permission: for the sake of information validation, I would like to record the interview. The recording will be kept secured and confidential with an access limited to the research team.

b. Personal background

b.1. What is your educational background and previous experience?

b.2. How long have you been working at this company? In what which positions and capacities?

b.3. What is your current position and what are your main responsibilities?

c. Functional area

c.1. Given your involvement with this function (department), what are the main responsibilities and objectives that this area contributes to?

c.2. What are the processes that you need to follow to fulfil these responsibilities and objectives?

c.3. What contributions and decisions do you need to make or participate in making within these processes? c.4. How does your function communicate and coordinate the results and the consequent processes that are triggered afterwards?

c.5. To the extent that you can tell, how are the processes that your function is involved with different from the processes related to other functions in the organization?

d. The COFP

d.1. Which of the main objectives your functional area contributes to is related to the order fulfilment process?

d.2. Based on your understanding, describe how the COFP at present is executed in terms of the activities that are included?

d.3. What is it that each activity is trying to achieve based on what you know about the whole process?

d.4. How does your function participate in these activities? I.e. what are the activities the function participates in? And how is this participation coordinated?

d.5. For each of the activities you participate in:

d.5.1. What is the rationale for that activity? I.e. why does the company/the working groups require the activity, or which goals the activity is trying to achieve?

d.5.2. Why does your functional area do, or is required to participate in doing that?

d.5.3. If applicable, which functions does your function cooperate with and why? How is this cooperation coordinated in detail?

d.5.4. What does influence your function's ability to contribute to the activity goals? The ability to contribute here means the ability to make decisions and solve problems.

d.5.5. What does influence the quality and quantity of the contribution of your function in each activity? The contribution quality here means the degree of decisions' and solutions' effectiveness, and the quantity means the capacity needed to process information.

e. Follow up

e.1. Is there anything else to tell as to be aware of how the COFP is working and your interactions with the other functional areas?

e.2. Is there anyone else you recommend us to contact so as to get a better understanding of the objectives and inner workings of the COFP?

e.3. Could we contact you in the future for further clarifications in case some gaps or inconsistencies pop up from our notes? 